\title{
Dynamic perforation and compression tests of PMMA for a wide range of temperatures - experimental and preliminary numerical analysis
}

\author{
Maciej Klosak ${ }^{1 *}$, Alexis Rusinek ${ }^{2,4}$, Tomasz Jankowiak ${ }^{3}$, Zakaria El Qoubba ${ }^{1}$, Rodrigue Matadi Boumbimba ${ }^{2,4}$ and Amine \\ Bendarma $^{1,3}$ \\ ${ }^{1}$ Universiapolis, Technical University of Agadir, Agadir, Morocco \\ ${ }^{2}$ University of Lorraine, Laboratory of Microstructure Studies and Mechanics of Materials (LEM3), Metz, France \\ ${ }^{3}$ Poznan University of Technology, Institute of Structural Engineering, Poznan, Poland \\ ${ }^{4}$ University of Lorraine, Laboratory of Polymers Characterization, Faulquemont, France
}

\begin{abstract}
Experimental tests were carried out on poly(Methyl Methacrylate) (PMMA) in order to define its mechanical behaviour over a wide range of temperature. To reach high strain rate, perforation tests were performed within a wide range of temperatures using a high-performance oven, from room temperature to $130{ }^{\circ} \mathrm{C}$, above the glass transition temperature $\mathrm{T}_{\mathrm{g}}$. In addition, the results were confronted with compression tests previously obtained. Based on experiments, the temperature transition between fragile and ductile was defined. The material became fully ductile above $118{ }^{\circ} \mathrm{C}$ inducing no cracking and debris during the perforation process. The yield stress evolution as function of strain rate for various temperatures was modelled by using the cooperative model. The model predictions were in agreement with experimental data. Two material models developed by Richeton and Nasraoui were analysed, the latter was then implemented into the FE model to simulate perforation tests for a wide range of temperatures and strain rates. It was observed that the coupling strain rate-temperature is a key factor to predict the structure behaviour not only in terms of material behaviour but also in terms of dynamic failure.
\end{abstract}

\section{Introduction}

Many research works were performed on polymers to encourage their use as metal substitute in engineering applications. This is due to their light weight and reasonable cost. Moreover, as it was in case of metals, their strain rate or temperatures sensitivity were frequently defined and studied as in [1-2]. For polymer such as PMMA studied by [3-4], it was reported that the material was strain rate sensitive with a brittle behaviour under dynamic loading. The failure mode observed is mainly due to crazing induced by high hydrostatic tension on the surface of the material and generated fine cracks. To avoid quick failure under dynamic loading, it is possible to increase the initial temperature $T_{0}$ and to stay lower than the glass transition $_{g}$. For atactic PMMA, the glass transition temperature $\mathrm{T}_{\mathrm{g}}$ varies from $85^{\circ} \mathrm{C}$ to $165^{\circ} \mathrm{C}$.

Several techniques may be used to heat up the specimen which enables tests at high strain rates and different initial temperatures $\mathrm{T}_{0}$ [5-8]. Frequently the process of induction is used to heat up the specimens. However, this is not readily applicable for polymer materials, because of their insulating character. An electric spiral can also be used and fixed around the specimen to reach the temperature imposed. Some devices are also used where a system heats the specimen and when the imposed temperature is reached; a robotic device fixes the specimen between the two bars using Split Hopkinson Pressure Bars (SHPB) system. The last technique does not provide a homogeneous temperature distribution in the specimen. As it was discussed in several papers, when the specimen is fixed between the two bars at room temperature, it decreases by heat conductivity along the bar. It is difficult in this case to use the results for modelling without knowing the real temperature in the specimen mainly due to the strong temperature sensitivity of polymers. To avoid the problem, a special oven was developed for dynamic compression tests as reported in [9]. An equivalent innovative solution was also proposed for heating plate specimens for perforation tests.

\section{Equipment for specimens heating}

\subsection{Thermal chamber for ballistic tests}

To perform perforation tests at high impact velocity, a pneumatic gas gun was used (Figs 1 and 2). It allows to reach a maximum impact velocity $V_{0}$ of $125 \mathrm{~m} / \mathrm{s}$ for a projectile mass equal to $\mathrm{m}_{\mathrm{p}}=30 \mathrm{~g}$. In this work, the present apparatus is equipped with an oven. The

Corresponding author: klosak@e-polytechnique.ma 
temperature may vary from room temperature to a maximum temperature above the glass transition $\mathrm{T}_{\mathrm{g}}$. A waiting time of about $t \approx 20 \mathrm{~min}$ was estimated to heat up the specimen and to reach a uniform temperature distribution in the specimen. For it, a thermocouple was fixed in the middle of the reference plate to calibrate the oven. Another thermocouple was fixed inside the oven to enable a continuous temperature control. Using the previous set-up described, PMMA plates were subjected to perforation. The plate dimensions were $130 \mathrm{~mm} *$ $130 \mathrm{~mm}$ for thicknesses equal to $\mathrm{t}=3 \mathrm{~mm}$ and $\mathrm{t}=6 \mathrm{~mm}$.

First, in order to observe the temperature's effect on the material and structure behaviour, the initial impact velocity was kept constant and equal to $\mathrm{V}_{0} \approx 90 \mathrm{~m} / \mathrm{s}$. It corresponds to a constant kinetic energy of about $120 \mathrm{~J}$. Secondly, different impact velocities $V_{0}$ were tested for three initial temperatures $\mathrm{T}_{0}$ to define the ballistic curves and to estimate the ballistic limits depending on the initial temperature.

The oven used for the test is presented Fig. 1. A hot flux air is flowing around the specimen plate as shown in Fig. 1. A sarcophagus is used around the plate specimen to have a uniform temperature distribution after a certain waiting time. Therefore, the two sides of the specimen are heat up in the same time. After it, due to conductivity the entire specimen is heated to reach the initial temperature imposed to the specimen and regulated by the controller.

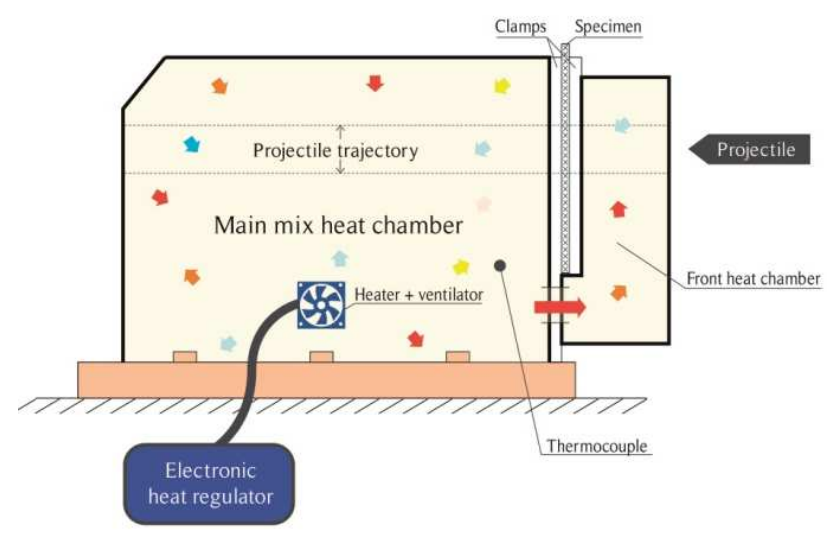

Fig. 1. Set-up used during perforation tests at wide range of temperatures.

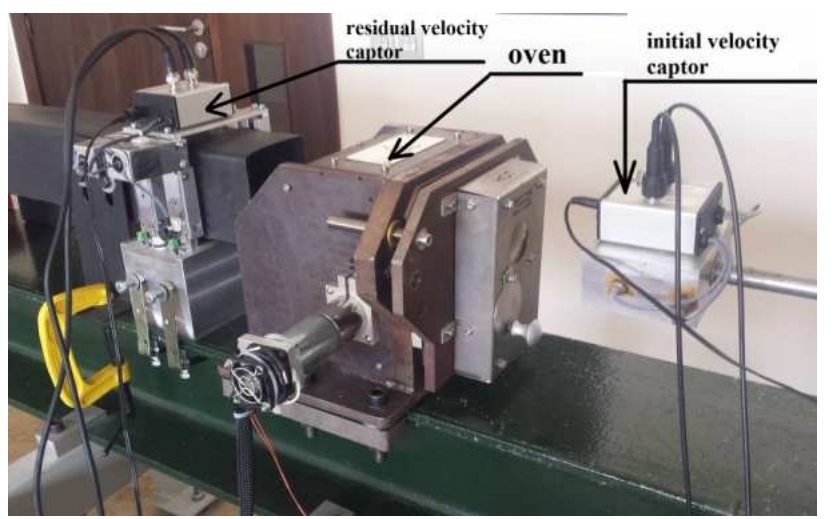

Fig. 2. Oven used for perforation tests at high impact velocity and high temperature.

\subsection{SHPB heating device}

A split-Hopkinson pressure bars apparatus (SHPB) was used to conduct uni-axial compression tests for strain rates higher than $1000 \mathrm{~s}^{-1}$. This apparatus consists of a blunt projectile, an incident bar, a transmitted bar, and a sample sandwiched between the incident and transmitted bars. The incident and transmitted bars have a diameter of $18 \mathrm{~mm}$. The length of the striker bar is $300 \mathrm{~mm}$ to obtain a loading time close to $t_{\text {loading }} \approx 120 \mu \mathrm{s}$. In order to define the material behaviour at high strain rates (up to $\left.\dot{\varepsilon} \geq 1000 \mathrm{~s}^{-1}\right)$ and high temperatures $\left(20^{\circ} \mathrm{C} \leq \mathrm{T}_{0} \leq\right.$ $140{ }^{\circ} \mathrm{C}$ ), experimental tests were performed using a specific oven fixed on the Split Hopkinson Pressure Bars (SHPB) [9]. This device allows to have a uniform temperature $\mathrm{T}_{0}$ in the volume of the specimen and to reduce the gradient of temperatures as discussed by Lennon and Ramesh [6]. The set-up developed and used for dynamic compression is schematically represented in Fig. 3.

The specimen dimensions are $8 \mathrm{~mm}$ in diameter and $4 \mathrm{~mm}$ in thickness.

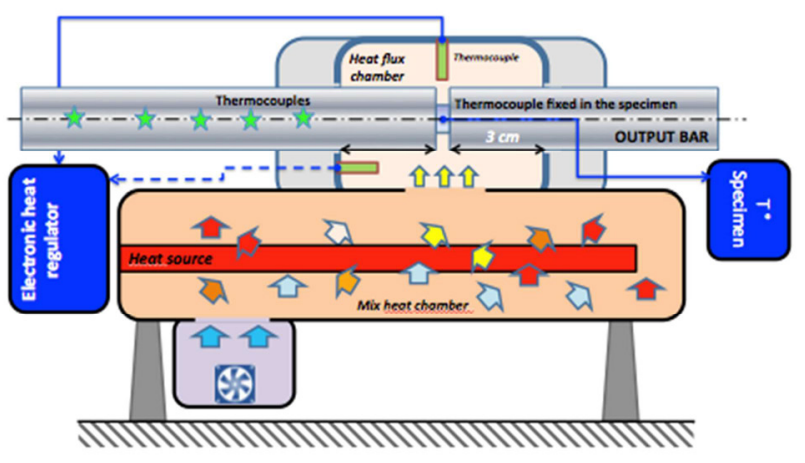

Fig. 3. Hopkinson Pressure Bars used during dynamic tests with an oven - description of the air flowing [9].

\section{Experimental results}

\subsection{Perforation}

Using the set-up described previously to reach different initial temperature, ballistic tests were performed. Some of the presented experimental results were already discussed in [9]. However, more experimental data are explored hereafter.

The results in terms of failure mode are reported in the following pictures, Fig. 4. Two typical failure behaviours were observed. For the tests performed at temperatures lower than the glass transition temperature (up to $80^{\circ} \mathrm{C}$ ), the plates failed with debris ejection and crack propagation. However, some ductility was observed around the hole compared with room temperature. For this case, the hole diameter corresponded to the diameter of the projectile. 


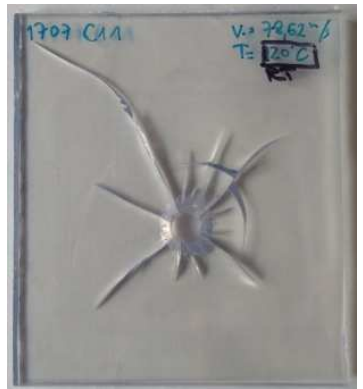

a)

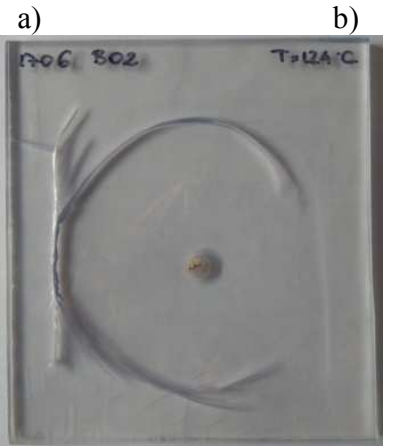

c)

Fig. 4. Perforation tests for different initial temperatures; a) 2 b) $118^{\circ} \mathrm{C}$, c) $124^{\circ} \mathrm{C}$; specimen thickness $6 \mathrm{~mm}$.

For a temperature close to $118^{\circ} \mathrm{C}$, the projectile went through the plate, but a crack was also observed along the clamped zone, Fig. 4b. When the temperature exceeded $118{ }^{\circ} \mathrm{C}$, the projectile perforated the plate and the impact hole closed without complete failure of the plate, Fig. 4c. The damage pictures are in agreement with PMMA behaviour generally observed. In fact, in glassy region, PMMA dissipates impact energy by cracks development. When the temperature increases and reaches a value closer to $\mathrm{T}_{\mathrm{g}}$, both cracks and cavitations become the main failure mode for PMMA.

During impact, cracks could be deflected by the presence of cavitations, explaining why at $80^{\circ} \mathrm{C}$ and 110 ${ }^{\circ} \mathrm{C}$, the cracks density is lower than the one at $20{ }^{\circ} \mathrm{C}$. Above $\mathrm{T}_{\mathrm{g}}$, the significant drop of the PMMA rigidity, and his ability to behave like a soft material, allow to explain the damage observed above $122^{\circ} \mathrm{C}$ [9].

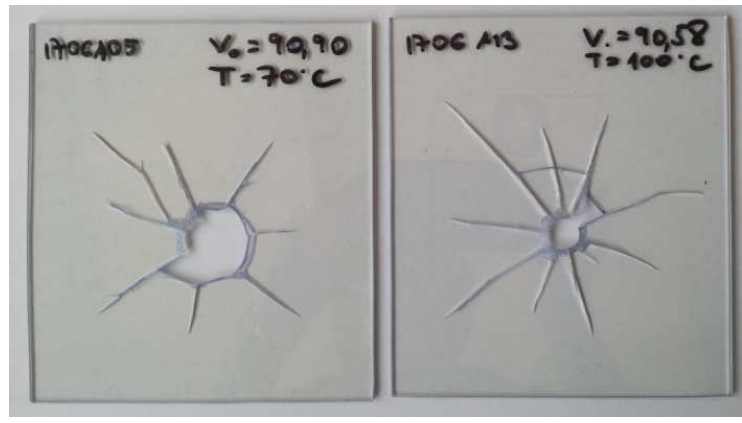

Fig. 5. Softening of material (fragile-ductile transition) perforation hole observed at different initial temperatures: a) $70^{\circ} \mathrm{C}$, b) $100{ }^{\circ} \mathrm{C}[9]$.

Figure 5 compares the diameter size of the perforation openings at different temperatures: $70{ }^{\circ} \mathrm{C}$ and $100{ }^{\circ} \mathrm{C}$. The diameter diminishes from $26 \mathrm{~mm}$ to $12 \mathrm{~mm}$, which can be translated by the temperature effect related to the softening of material. It can be assumed these temperatures values correspond to the transition between fragile to ductile behaviour.

Based on experiments, the residual velocity for an initial impact velocity $V_{0}$ was measured depending on the initial temperature, Fig. 6. It is possible to use the equation proposed by Recht et al. [10] to fit the data, Eq. 1.

$$
\mathrm{V}_{\mathrm{R}}=\left(\mathrm{V}_{0}^{\alpha}-\mathrm{V}_{\mathrm{B}}^{\alpha}\right)^{1 / \alpha}
$$

where $V_{0}$ is the initial impact velocity, $V_{B}$ is the ballistic limit and $\alpha$ is a fitting parameter.

Figure 6 reports a comparison between experimental results at room temperature, $70{ }^{\circ} \mathrm{C}$ and $110{ }^{\circ} \mathrm{C}$ for $6 \mathrm{~mm}$ plate thickness. It can be observed that increasing the initial temperature of the specimen shifts the ballistic limit (state of no perforation) to lower values: the ballistic limit estimated at room temperature is $39{ }^{\circ} \mathrm{C}$ and decreases to $33{ }^{\circ} \mathrm{C}$ at the temperature of $110{ }^{\circ} \mathrm{C}$ [9].

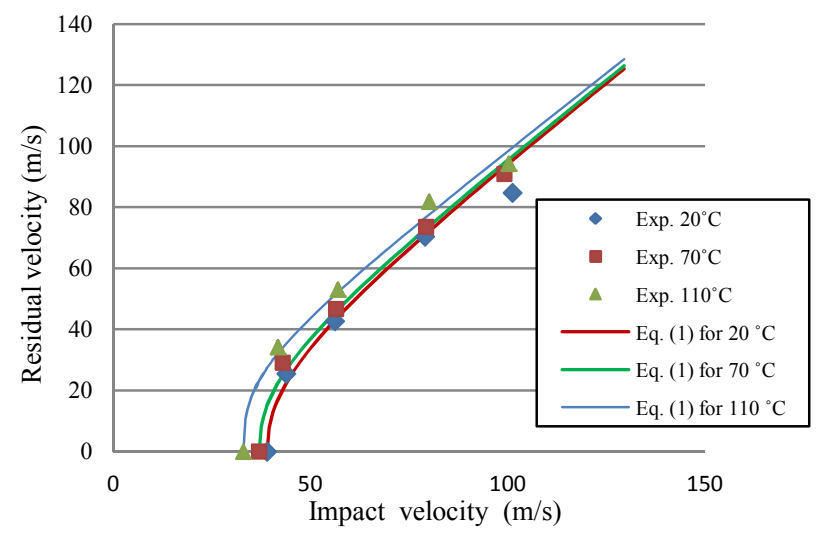

Fig. 6. Impact velocity $\mathrm{V}_{0}$ vs residual velocity $\mathrm{V}_{\mathrm{R}}$ experimental results for $\mathrm{T}=20{ }^{\circ} \mathrm{C}, \mathrm{T}=70{ }^{\circ} \mathrm{C}$ and $\mathrm{T}=110{ }^{\circ} \mathrm{C}$; specimen thickness $=6 \mathrm{~mm}$.

The parameter $\alpha$ in Eq. 1 changes depending on the initial temperature, see Table 1. Based on it, the failure energy $E_{\text {failure }}$ may be estimated, Eq. 2. This energy values are discussed further in Fig. 8.

$$
\mathrm{E}_{\text {failure }}=\frac{\mathrm{m}_{\mathrm{P}}}{2}\left(\mathrm{~V}_{0}^{2}-\mathrm{V}_{\mathrm{R}}^{2}\right)
$$

Table 1. Parameter depending on the initial temperature [9].

\begin{tabular}{lll}
\hline $\begin{array}{l}\boldsymbol{\alpha}_{20} \\
(-)\end{array}$ & $\begin{array}{l}\boldsymbol{\alpha}_{\mathbf{7 0}} \\
(-)\end{array}$ & $\begin{array}{l}\boldsymbol{\alpha}_{\mathbf{1 1 0}} \\
(-)\end{array}$ \\
\hline 2.21 & 2.3 & 2.8 \\
\hline
\end{tabular}

It is observed from these experiments that coupling strain rate-temperature is a key factor to predict the structure behaviour not only in terms of mechanical response during loading, but also in terms of dynamic failure.

More results about the ballistic limit were gathered for thinner $3 \mathrm{~mm}$ plates. It was observed that the ballistic limit remained practically independent of the temperature. The values recorded were 11-12 m/s. 
However, different failure modes were observed. As it is reported in Fig. 7, material is fully brittle for $20{ }^{\circ} \mathrm{C}$, see Figs $7 \mathrm{a}$ and $7 \mathrm{~b}$ (similar behaviour was still observed up to $80{ }^{\circ} \mathrm{C}$ ). At $110{ }^{\circ} \mathrm{C}$, the material became fully soft. Above the ballistic limit the projectile was passing through the specimen with the closure of the perforation whole (Fig. 7d). However, for the impact velocities lower than the ballistic limit, the projectiles bounced from the specimen which finally experienced permanent plastic deformation as it is clearly visible in Fig. 7c.

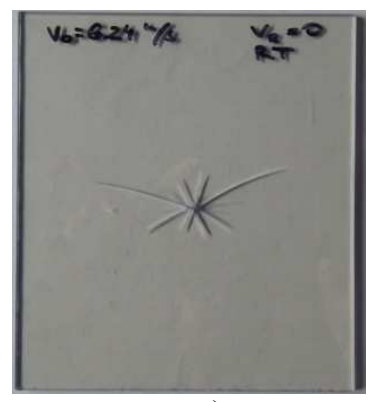

a)

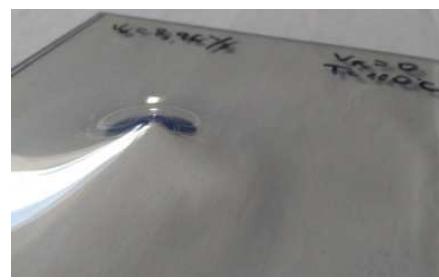

c)

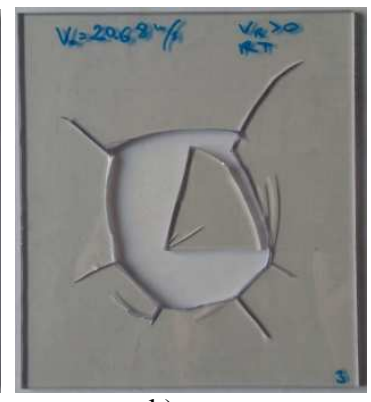

b)

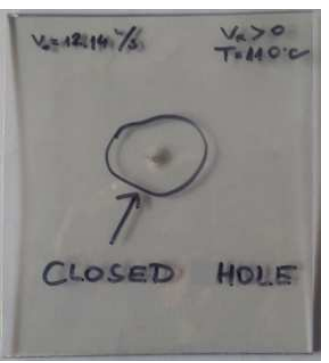

d)
Fig. 7. Failure modes close to the ballistic limit a) no perforation at $\mathrm{V}_{0}=6,24 \mathrm{~m} / \mathrm{s}, 20{ }^{\circ} \mathrm{C}, \mathrm{b}$ ) perforation at $\mathrm{V}_{0}=20,68$ $\mathrm{m} / \mathrm{s}, 20{ }^{\circ} \mathrm{C}$, c) no perforation at $\mathrm{V}_{0}=8,96 \mathrm{~m} / \mathrm{s}, 110{ }^{\circ} \mathrm{C}$, d) perforation at $\mathrm{V}_{0}=12,14 \mathrm{~m} / \mathrm{s}, 110{ }^{\circ} \mathrm{C}$.

The results presented in Fig. 8 show that the energy dissipated during the perforation process does not depend on temperature. It has to be noted that all the results reported were obtained with the same initial impact velocity, $\mathrm{V}_{0}=90-91 \mathrm{~m} / \mathrm{s}$. The average dissipated energy calculated through Eq. 2 is about $24,2 \mathrm{~J}$ for $3 \mathrm{~mm}$ specimens and close to $58,4 \mathrm{~J}$ for $6 \mathrm{~mm}$ thickness. At high temperatures above $T_{g}$ the results are more dispersive due to the apparition of the extra crack around the clamped zone (compare Figs $4 \mathrm{~b}$ and $4 \mathrm{c}$ ).

On the other hand, the 3 and $6 \mathrm{~mm}$ plates subjected to high impact velocities of the value of approximately $91 \mathrm{~m} / \mathrm{s}$ did not reveal much resistance, the mean residual velocity is $84 \mathrm{~m} / \mathrm{s}$ and $64,5 \mathrm{~m} / \mathrm{s}$, respectively for $3 \mathrm{~mm}$ and $6 \mathrm{~mm}$ specimens.

\subsection{Compression tests}

The SHPB setup validation and characterization of PMMA at high temperature was done through an extended testing programme [9]. Some results are presented hereafter. Figure 9 shows the different results obtained during the dynamic compression tests at an average strain rate of $2444 \mathrm{~s}^{-1}$ and at various temperatures, varying from room temperature to $140{ }^{\circ} \mathrm{C}$. As expected, stress-strain curves of PMMA are characterized by an elastic region, a yield point, strain softening and a failure zone. Obviously, both Young modulus and yield stress decrease as the test temperature increases. This decrease is more significant when the test temperature is near to the glass transition temperature $T_{g}$.

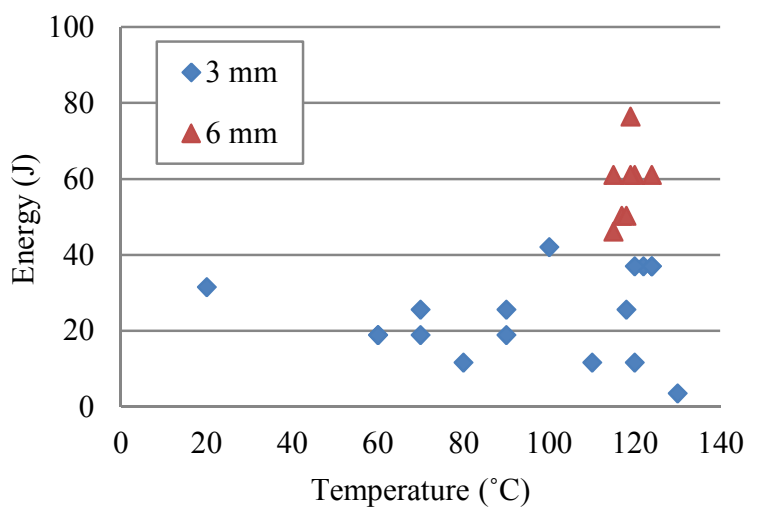

Fig. 8. Dissipated energy at different selected temperatures for $3 \mathrm{~mm}$ and $6 \mathrm{~mm}$ specimen thicknesses.

Moreover, the PMMA undergoes a significant softening before fracture for the test temperature located in the glassy region. When the temperature increases to reach the glass transition region, the slope of the softening region decreases. The analysis of Fig. 9 enables to verify the time-temperature equivalence by displaying stress-strain curves for different temperatures. Indeed, it can be observed that an increase in testing temperature causes the opposite effect of a strain rate increase.

The influence of the strain rate on the mechanical behaviour of PMMA was also analysed. The results indicate that PMMA is strain rate sensitive. One can also notice an increase of the Young modulus and the yield stress when the strain rate rises. At $70{ }^{\circ} \mathrm{C}$, and for high strain rates a large plastic domain is observed [9].

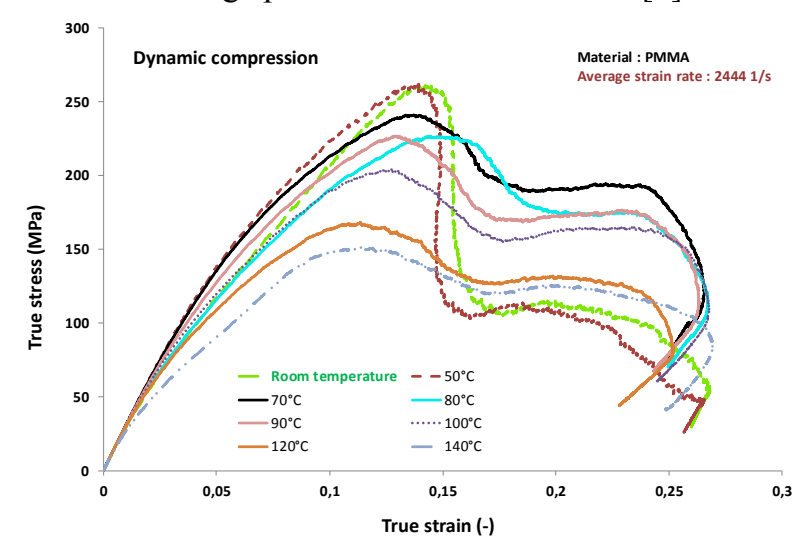

Fig. 9. Strain rate effect on PMMA behaviour at room temperature [9].

\section{Constitutive relation}

Several models were published in the international literature to describe the material behaviour observed for polymers. For example, based on the works of 
Fotheringham et al. [11] and Fotheringham and Cherry [12], the cooperative model proposed by Richeton et al. [1] may be written as:

$\sigma_{\mathrm{y}}(\dot{\varepsilon}, \mathrm{T})=\sigma_{\mathrm{i}}(0)-\mathrm{mT}+\frac{2 \mathrm{KT}}{\mathrm{V}} \sinh ^{-1}\left(\frac{\dot{\varepsilon}}{\dot{\varepsilon}_{0} \exp \left(-\frac{\Delta \mathrm{H}_{\beta}}{\mathrm{KT}}\right)}\right)^{1 / \mathrm{n}}$

where $\sigma_{i}, K, V, \dot{\varepsilon}_{0}, \Delta \mathrm{H}_{\beta}$ respectively the internal stress, Boltzmann constant, activation volume, characteristic strain rate, and activation energy, $m$ and $n$ are material parameters.

Nasraoui et al. [13] proposed a constitutive equation based on the work of G'sell and Jonas [14] as follow:

$$
\begin{aligned}
& \sigma(\varepsilon, \dot{\varepsilon}, \mathrm{T}, \mathrm{P}) \\
& =\left(1-\mathrm{T} / \mathrm{T}_{\mathrm{g}}\right)(1 \\
& -\exp (-\mathrm{w} \varepsilon))\left[\sigma_{1} \exp (-\mathrm{b} \varepsilon)\left(\dot{\varepsilon} / \dot{\varepsilon}_{01}\right)^{\mathrm{m} 1}\right. \\
& +\sigma_{2} \exp \left[\left(\mathrm{h}_{0}+\mathrm{h}_{1} \frac{\mathrm{T}-\mathrm{T}_{\text {ref }}}{\mathrm{T}_{\text {ref }}}\right)\left(\varepsilon^{2}\right)\left(1+\left(\dot{\varepsilon} / \dot{\varepsilon}_{02}\right)^{-1}\right)^{-\mathrm{m} 2}\right]
\end{aligned}
$$

$\mathrm{T}$ and $\mathrm{T}_{\mathrm{g}}$ are respectively the absolute and the glass transition temperature. $\mathrm{T}_{\text {ref }}$ is the reference temperature, taken at $298 \mathrm{~K} . \varepsilon$ is the true strain and $\dot{\varepsilon}_{01}$ is the reference strain rate equal to $0.1 \mathrm{~s}$. Other parameters $\mathrm{w}$, $\mathrm{b}, \mathrm{h}_{0}, \mathrm{~h}_{1}, \mathrm{~m} 1, \mathrm{~m} 2, \sigma_{1}$ and $\sigma_{2}$ are material parameters. $\sigma_{1} \exp (-\mathrm{b} \varepsilon)\left(\dot{\varepsilon} / \dot{\varepsilon}_{01}\right)^{\mathrm{m} 1}$ represents the yield stress and the strain softening after the peak stress whereas the term $\sigma_{2} \exp \left(\left(\mathrm{h}_{0}+\mathrm{h}_{1} \frac{\mathrm{T}-\mathrm{T}_{\mathrm{ref}}}{\mathrm{T}_{\mathrm{ref}}}\right)\left(\varepsilon^{2}\right)\left(1+\left(\dot{\varepsilon} / \dot{\varepsilon}_{02}\right)^{-1}\right)^{-\mathrm{m} 2}\right.$ depicts the strain hardening behaviour during plastic deformation.

The proposed model was compared to experimental values obtained from low to high strain rates under compression [13]. A good agreement was observed. The constants are reported in Table 2. These results will be adopted for further preliminary numerical simulations.

Table 2. PMMA material parameters used for the cooperative Nasraoui model [13].

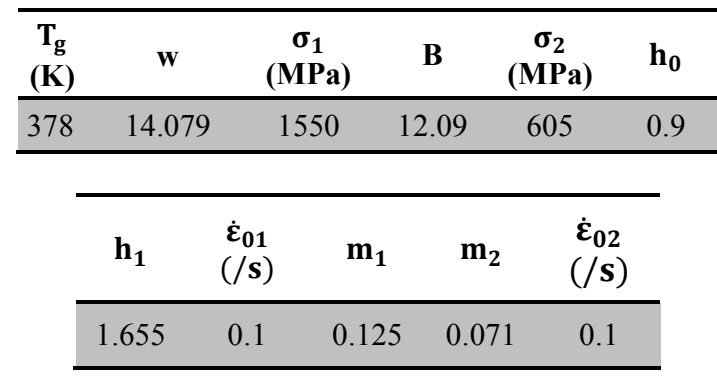

\section{Preliminary numerical simulations}

Two failure criteria which are available in Abaqus Explicit were discussed: tensile failure value and ductile failure with damage evolution. The failure criteria can be applied separately or combined without any need of the user subroutine. Finally, the damage initiation criterion was selected and values were fitted in order to mimic experimental behaviour.

The following ballistic limits were obtained: $50 \mathrm{~m} / \mathrm{s}$ for $6 \mathrm{~mm}$ specimen thickness and $35 \mathrm{~m} / \mathrm{s}$ for $3 \mathrm{~mm}$ which is above experimental values. On the other hand, the material proposed reflects typical damage evolution observed during experiments.

Some results are shown in Figs 10-11 in which vonMisses stresses as well as the plastic deformations are presented for two specimen thicknesses for the initial impact velocity of $90 \mathrm{~m} / \mathrm{s}$ and the assumed loading time.
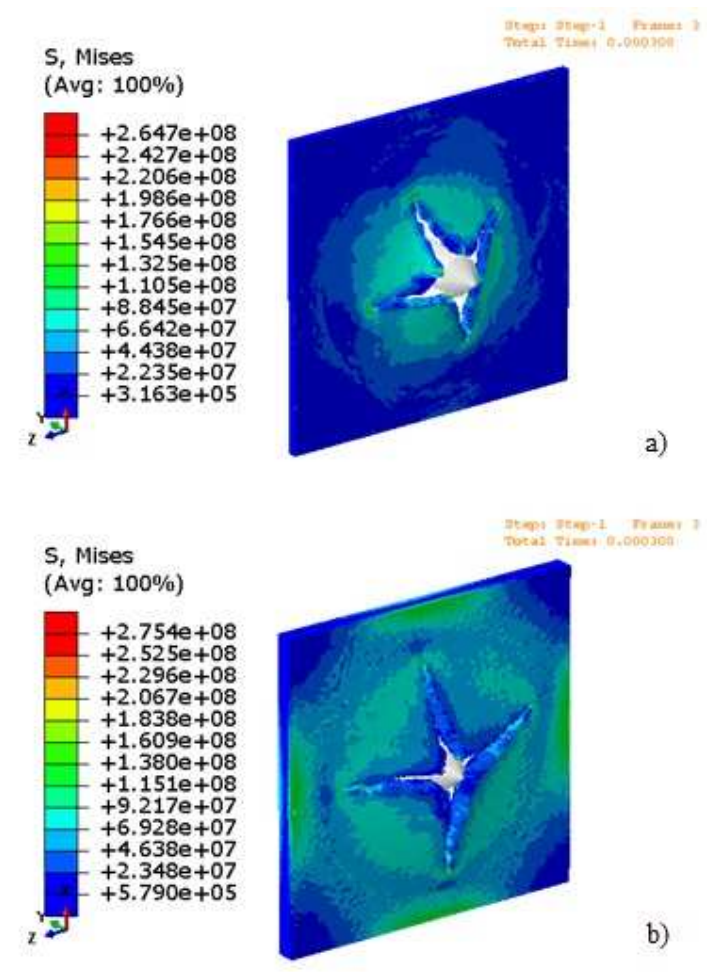

Fig. 10. Preliminary numerical results for PMMA perforation tests: von-Mises stress distribution; testing conditions: room temperature, $V_{0}=90 \mathrm{~m} / \mathrm{s}$ a) specimen thickness $3 \mathrm{~mm}, \mathrm{~b}$ ) specimen thickness $6 \mathrm{~mm}$. 

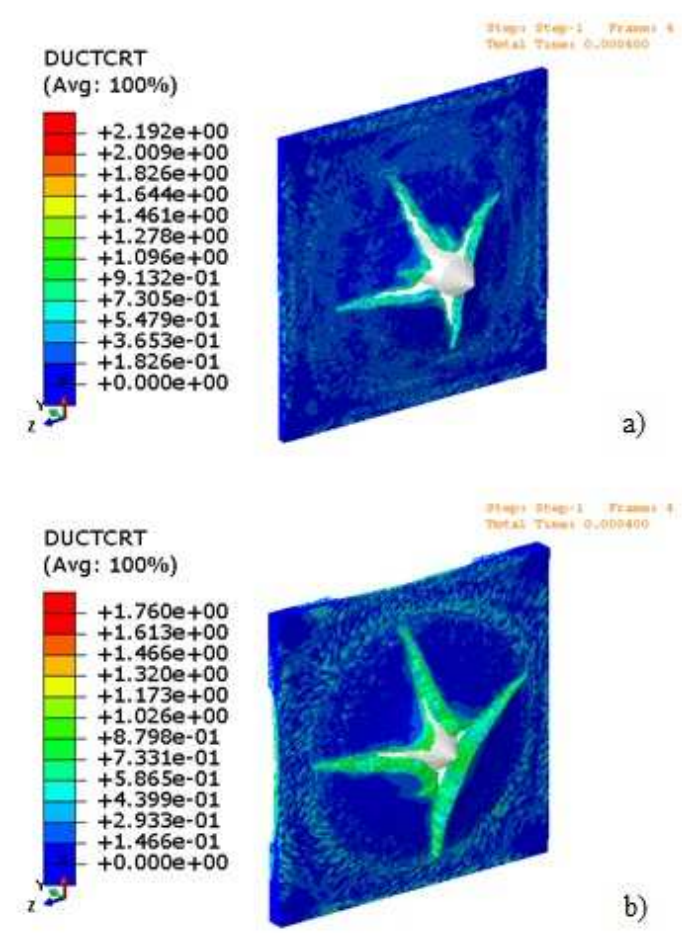

Fig. 11. Preliminary numerical results for PMMA perforation tests: plastic strain distribution; testing conditions: room temperature, $V_{0}=90 \mathrm{~m} / \mathrm{s}$ a) specimen thickness $3 \mathrm{~mm}$, b) specimen thickness $6 \mathrm{~mm}$.

\section{Conclusions}

The principal aim of the study was to check the effectiveness of the new experimental technique in which perforation and compression tests were performed within a wide range of temperatures, starting from room temperature to $140{ }^{\circ} \mathrm{C}$. It was expected to prove the repeatability of experimental results with heated specimens (stabilization of temperature in the thermal chamber). It can be concluded that the thermal chamber set-ups have proved its designed performances and opened new perspectives to carry out perforation tests in the wide range of temperatures both for perforation and compression tests. This innovative testing methodology allows verifying material behaviour in conditions which could be so far only analysed numerically or analytically.

Important results were obtained for PMMA heated to elevated temperatures. Dynamic compression and perforation validation tests conducted on PMMA revealed strain rate and temperature dependence. The perforation tests demonstrated a fragile-ductile transition over $100{ }^{\circ} \mathrm{C}$.
The Nasraoui approach allowed determining the brittle ductile transition of the PMMA. Correlation between the numerical simulations and experimental data are in good agreement.

This work will be extended in future to others polymer and polymer based composite materials.

The study was possible due to the technical support provided by Tomasz Libura from the Institute of Fundamental Technological Research of the Polish Academy of Sciences. Concerning the presented thermal chamber for ballistic tests, the patent application has been submitted to OMPIC Morocco with the reference number 41383 on October 31, 2017.

\section{References}

1. J. Richeton, S. Ahzi, K.S. Vecchio, F.C. Jiang, R.R. Adharapurapu, Int. J. Solids Struct. 43, 2318 (2006)

2. A.D. Mulliken, M.C. Boyce, Int. J. Solids Struct. 43, 1331 (2006)

3. A. Dorogoy, D. Rittel, Mech. Mater. 70, 53 (2014)

4. D. Rittel, A. Dorogoy, Mech. Mater. 70, 41 (2014)

5. P. Forquin, M. Nasraoui, A. Rusinek, L. Siad, Int. J. Impact Eng. 40, 46 (2012)

6. A.M. Lennon, K.T. Ramesh, Int. J. Plasticity 14 , 1279 (1998)

7. Y. Li, Y. Guo, H. Hu, Q. Wei, A, Int. J. Impact Eng. 36, 177 (2009)

8. K. Wang, N. Bahlouli, R.M. Boumbimba, F. Addiego, Y. Rémond, JDBM 2, 101 (2016)

9. A. Rusinek, R. Bernier, R. Matadi Boumbimba, M. Klosak, T. Jankowiak, G.Z. Voyiadjis, Polym. Test. 65, 1 (2018)

10. R.F. Recht, T.W. Ipson, J. Appl. Mech, 30 (3), 384 (1963)

11. D.G Fotheringham, B.W. Cherry B.W., J. Mater. Sci., 11, 1368 (1976)

12. D.G Fotheringham, B.W. Cherry B.W., J. Mater. Sci., 13, 951 (1978)

13. M. Nasraoui, P. Forquin, L. Siad, A. Rusinek, Mater. Des. 37, 500 (2012)

14. C. G'sell, J.J. Jonas, J. Mater. Sci., 14, 583 (1979) 